University of Wollongong

Research Online

Faculty of Business - Papers (Archive)

Faculty of Business and Law

2013

Eagles and turkeys: Human capital externalities, departmental coauthorship and research productivity

Frank Neri

University of Wollongong, fneri@uow.edu.au

Joan R. Rodgers

University of Wollongong, jrrodger@uow.edu.au

Follow this and additional works at: https://ro.uow.edu.au/buspapers

Part of the Business Commons

Research Online is the open access institutional repository for the University of Wollongong. For further information contact the UOW Library: research-pubs@uow.edu.au 


\title{
Eagles and turkeys: Human capital externalities, departmental co-authorship and research productivity
}

\begin{abstract}
Lucas (1988) hypothesised that human capital externalities explain persistent productivity growth and become manifest via interactions between workplace colleagues. Consistent with the first part of this hypothesis, Fox and Milbourne (2006) concluded that an increase in the average level of human capital in Australian economics departments raised the research productivity of departmental members. This paper tests the robustness of this finding by using a direct, rather than a proxy, measure of human capital and confirms the existence of human capital externalities within Australian economics departments. But we extend the analysis in two important dimensions. Firstly, we investigate the second part of Lucas' hypothesis by testing whether the externality becomes manifest via co-authoring. We find no evidence that this type of interaction is associated with higher research productivity, especially for higher quality outputs. Secondly, we control for the likely endogeneity of one's peer group via instrumental variables estimation. In this case, we find that the peer group effect disappears completely for the highest quality outputs but remains for research output more broadly defined.
\end{abstract}

\section{Keywords \\ era2015 \\ Disciplines \\ Business}

\section{Publication Details}

Neri, F. \& Rodgers, J. R. (2013). Eagles and turkeys: Human capital externalities, departmental coauthorship and research productivity. Australian Economic Papers, 52 (3-4), 171-189. 


\title{
EAGLES AND TURKEYS: HUMAN CAPITAL EXTERNALITIES, DEPARTMENTAL CO-AUTHORSHIP AND RESEARCH PRODUCTIVITY
}

\author{
FRANK NERI and JOAN R. RODGERS* \\ University of Wollongong
}

Key Words: Human capital, peer effects, co-authoring.

\begin{abstract}
Lucas (1988) hypothesised that human capital externalities explain persistent productivity growth and become manifest via interactions between workplace colleagues. Consistent with the first part of this hypothesis, Fox and Milbourne (2006) concluded that an increase in the average level of human capital in Australian economics departments raised the research productivity of departmental members. This paper tests the robustness of this finding by using a direct, rather than a proxy, measure of human capital and confirms the existence of human capital externalities within Australian economics departments. But we extend the analysis in two important dimensions. Firstly, we investigate the second part of Lucas’ hypothesis by testing whether the externality becomes manifest via co-authoring. We find no evidence that this type of interaction is associated with higher research productivity, especially for higher quality outputs. Secondly, we control for the likely endogeneity of one's peer group via instrumental variables estimation. In this case, we find that the peer group effect disappears completely for the highest quality outputs but remains for research output more broadly defined.
\end{abstract}




\section{INTRODUCTION}

Microeconomists have long recognised that externalities affect economic efficiency. Over the last 25 years macroeconomists have also developed an interest in externalities, in particular because of their potential for explaining persistent productivity differentials among countries. For example Lucas (1988) hypothesised that, additional to the usual inputs (technology, physical and human capital), production also depends on a human capital externality, which he modelled as increasing in the average skill level of workers. Subsequently, there has been some interest in identifying and quantifying human capital externalities within workplaces.

According to this literature, positive human capital externalities within firms may emerge from the creation of a team ethos, from information sharing, from skill complementarities, and from informal on-the-job training amongst co-workers. The existence of positive human capital externalities is suggested by the clustering of highly skilled professionals (and non-professionals) in firms and by team dynamic effects in professional sport. Conversely, human capital externalities may be negative if over-qualified workers are disruptive or if an excessive variation in human capital across workers in a firm creates a skills-incompatibility problem which makes it difficult to implement training programs, increases the costs of co-ordination and communication or promotes fractionalisation within the workplace. In this latter scenario more highly skilled workers may discount the productive potential from collaborating with their less skilled colleagues. ${ }^{\mathrm{i}}$

Whilst there is a large body of empirical work that tests for such effects in schools, other workplace settings have attracted less attention. Recent exceptions include Mas and Moretti (2009) who find evidence of positive productivity spillovers among cashiers employed by a supermarket chain in the USA, Guryan et al. (2009) 
who find no evidence of performance spillovers among male professional golfers on the PGA tour, and Borjas and Doran (2012) who find a negative productivity spillover on US mathematicians after the large influx of Soviet mathematicians post 1990. Our interest lies with the existence of human capital externalities in Australian academia. Academics typically possess high levels of human capital which are relatively easily identified and so the human capital externality hypothesised by Lucas should be measurable within academia. However the literature examining this workplace issue is sparse.

Fox and Milbourne (1999) and Rodgers and Neri (2007) both found that the research productivity of academic economists in Australia is associated with their own human capital and the characteristics of their departmental environment. Additionally, and of most relevance to this study, Fox and Milbourne (2006, from here on referred to as FM) found evidence consistent with a positive human capital externality within economics departments in Australia. The authors collected survey data from 134 academics on their human capital and other characteristics, and on the institutional environment in which they worked. Human capital data included whether the academic had a $\mathrm{PhD}$, the time taken to obtain the $\mathrm{PhD}$ and the grade of the Honours degree. Institutional data included the individual's average teaching hours per week, average class size and the average number of research grants held per year since the first appointment in an academic position.

The authors calculated various proxy measures of the human capital of the coworkers of the academics who responded to the questionnaire, all based on their lifetime research output. These included the average annual research output of the most productive individual, of the three most productive individuals and of the most productive quartile in the relevant department. ${ }^{\text {ii }}$ The authors concluded, on the basis of 
Tobit regressions in which the coefficient on the proxy for the average human capital of one’s departmental colleagues was statistically significant and positive: "...there are human capital externalities so that an increase in the human capital of any individual also raises, at the margin, the productivity of others. There is some evidence to suggest that the externality is driven primarily by having a small but critical mass of researchers, rather than one outstanding individual." (p. 369).

This paper tests the robustness of this conclusion but differs from FM in several important dimensions. Firstly we examine a different study period and our database covers nearly all Australian academic economists rather than just a selfselected sample who responded to a survey. Secondly we use direct rather than proxy measures for the human capital of one's departmental colleagues. Thirdly we investigate whether the externality becomes manifest via co-authoring among departmental peers. Finally, and perhaps most importantly, we use instrumental variables estimation to test whether the peer effect is robust to the assumption that one’s peer group is endogenously rather than randomly determined. ${ }^{\text {iii }}$

The remainder of the paper is organised as follows. In the next section we present and discuss our data. In section III we estimate an econometric model of the determinants of research productivity. Finally, section IV concludes.

\section{DATA}

We identified all academics at the level of Lecturer (Level B) and above in 28 research active Australian economics departments during the period 1996-2000 and constructed a dataset of their research productivity and human capital. ${ }^{\text {iv,v }}$ We took account of publication time lags by assuming that a given publication was produced within the department stated in the affiliation if and only if an author was a member of 
the department two years prior to the publication year. Publications were classified as departmentally co-authored if and only if at least two of the authors appeared on one of our departmental staff lists. ${ }^{\mathrm{vi}}$

We counted only refereed journal publications because we are interested in research of a minimum level of quality (Neary, Mirrlees and Tirole, 2003). ${ }^{\text {vii }}$ Our major source of publications data was the on-line version of EconLit. This database is not without limitations (Pomfret and Wang, 2003), a major one being that articles with several authors are frequently referenced using the 'et al.' convention.

Consequently relevant articles will be missed unless the first author is included in our staff list and a supplementary search is undertaken to reveal the other authors, a practice which we followed in every case. We also used sources such as departmental reports and CVs to identify articles where the first author is not in our lists but another author is. Each of $n$ authors received credit for $1 / n$ of the article.

We calculated departmental research productivity as the weighted average of the research productivities of its members, the weights being the number of years each member was in the department from 1996 to 2000. The individual's research productivity was computed as his or her publication output per year resulting from work undertaken during the period 1996 through 2000 when the individual was employed in the department. We assumed that longer articles imply a larger research output and so we took page counts but adjusted these for differences in the mean number of words or characters per page. viii

Any meaningful measure of departmental research productivity must also take account of journal quality which is particularly relevant here because co-authorship may be more common where colleagues attempt to publish in top tier journals. However, measuring journal quality is problematic. ${ }^{\text {ix }}$ Consequently we used two 
versions of our dataset on departmental research productivity. The first (which we term Q1) weights page counts by the impact factors of only the top 159 journals from Kalaitzidakis, Mamuneas and Stengos (2003), which were derived from citation counts for journals published over a ten year period. Ipso facto, this approach disregards publications in many other journals which are of insufficient quality. The weights also emphasise publications in a small subset of the 159 journals, only 29 of which receive a weight greater than 0.1 .

As relatively few Australian academic economists published in top tier journals, and on the assumption that any article in a refereed journal is better than no article at all, we also used a much larger dataset (termed Q2) which includes articles published in any of the 1036 journals covered by EconLit, including the 159 in our Q1 database. Following Gibson (2000) and Towe and Wright (1995), the journals were divided into four groups with journal quality weights of 1.00, 0.64, 0.34 and 0.05, respectively.

One criticism of our methodology is that journal quality weights are only imprecise proxies for individual article quality. For example, Oswald (2007) has argued that there exists greater quality variation within journals than there exists across journals. However Oswald's analysis is based on only six high quality journals, four of which (American Economic Review, Econometrica, Journal of Public Economics and Economic Journal) are commonly ranked in the top 20 journals worldwide. On the other hand our databases, which include publications in 159 journals (Q1) and 1036 journals (Q2), are so large that the quality variation within journals is likely to be swamped by the quality variation across journals. Nevertheless we acknowledge that there will be criticisms of our journal lists and the quality 
relativities we use. The fact is that any weighting scheme is to a greater or lesser extent ad hoc. Our approach is explicit and replicable using alternate weights.

Table I presents (alphabetically) our departmental data on research productivity and on the percentage of that research output that was co-authored by (at least two) departmental colleagues. Column 2 of Table I shows the percentage of academics in each department with positive Q1 publications during the study period. Because many academics in many departments did not publish at all, we present in Column 3 the Q1 research productivities of the subset of academics in each department who had positive publications. Column 4 contains departmental Q1 research productivities for all academics, which range from a minimum of zero to a maximum of 0.66 quality-weighted pages per person year. Whilst for all departments the productivity figures are much higher for the research active than for all members, in some cases by as much as sevenfold (e.g. Macquarie and UTS), the data nevertheless highlight the fact that during the study period the large majority of Australian academic economists had low research productivity by international

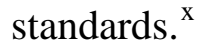

Column 5 of Table I contains the proportions of the departmental Q1 outputs that were co-authored with departmental colleagues and the range is again very wide, from a minimum of zero per cent to a maximum of 74.5 per cent. Columns 6-9 of Table I contain the corresponding data for Q2 publications. Departments are more productive in terms of Q2 publications, with productivity of the research-active ranging from 0.19 to 5.40 pages per person per year (Column 7) and that of all members ranging from 0.05 to 2.77 (Column 8). Finally Column 9 contains the respective proportions co-authored by colleagues, the range being very similar to that for Q1 productivity. 
\{Table I here\}

Table I clearly indicates that research productivity, whether measured for a restricted or a much broader collection of journals, was low on average across all departments and was driven in most departments by a relatively small group of active researchers. These data also suggest that attitudes or traditions towards co-authoring with colleagues within departments varied greatly. In some departments, as much as 75 per cent of all journal articles were authored by departmental colleagues. In other departments, such collaboration was simply non-existent.

Of particular interest to us is whether departmental co-authorship is positively related to research productivity. The last row of Columns 5 and 9 in Table I contains the simple correlation coefficients between, respectively, Q1 and Q2 departmental research productivities and the relevant proportions co-authored. In both cases there is a weak negative correlation between these two variables. Thus if positive research externalities exist, they do not become manifest via co-authorship between departmental colleagues, at least not as measured by simple correlations based on department-level data. In the next section we investigate the relationships between research productivity, human capital and co-authorship ceteris paribus with data at the level of the individual.

\section{MODELLING RESEARCH PRODUCTIVITY}

In this section we investigate the existence and nature of a human capital externality by estimating models of the determinants of research productivity using data for individual academics. As a substantial proportion of academic economists in our data set have zero publications, we use a Tobit (Type I) model which allows for corner solutions. Equation (1) states the hypothesis that research output is related to human 
capital, research experience, a human capital externality and a variable for coauthoring, plus a set of controls: ${ }^{\mathrm{xi}}$

$$
\begin{aligned}
& \log (\text { output })=\max \left[\text { lower limit, } \beta_{0}+\beta_{1} \text { phd } 1+\beta_{2} \text { phd } 2+\beta_{3} \text { phd } 3+\beta_{4}\right. \text { exp } \\
& +\beta_{5}(\text { phd } 1 * \text { exp })+\beta_{6}(\text { phd } 2 * \text { exp })+\beta_{7} \text { female }+\beta_{8} \text { prof }+\beta_{9} \text { aspro }+\beta_{10} \text { resuni } \\
& \left.+\beta_{11} \text { size }+\beta_{12} \text { studstaff }+\beta_{13} \text { resexpend }+\gamma_{0} \text { externality }+\gamma_{1} \text { co-author }+u\right]
\end{aligned}
$$

The lower limit is set just below the logarithm of the smallest positive research output in the data set and outputs equal to zero have their logarithms set at this lower limit (see Cameron and Trevedi, 2009, Section 16.4.2). ${ }^{\text {ii }}$ The dependent variable is the logarithm of research output because, unlike research output itself, the logarithm was found to be approximately normally distributed over strictly positive output values. The error term, $u$, represents unobservable influences on output and is assumed to be $\operatorname{Normal}\left(0, \sigma^{2}\right)$.

The human capital of individual academics is represented by three dummy variables, phd1, phd2 and phd3, which equal one if, in the first year between 1996 and 2000 that the individual was employed in a given department, he or she had a $\mathrm{PhD}$ from an institution ranked $1-50,51-150$ or $\geq 151$, respectively (in descending quality order). ${ }^{\text {xii }}$ Experience, exp, is the number of years between when the $\mathrm{PhD}$ was conferred and the last year between 1996 and 2000 that the individual was employed in the given economics department. Individuals without a $\mathrm{PhD}$ have exp set equal to zero; they constitute the benchmark category to which others are compared. The two interaction terms allow experience to have a differential effect on research output, depending on the quality of the PhD. 
Several control variables, reflecting characteristics of the individual, are also included in the model. The binary variable female, controls for any productivity differences between male and female academic economists. Two binary variables attempt to control for research ability and ambition to climb the academic ladder: prof, which equals one if the individual was a professor when first observed in the department, and aspro which equals one if the individual was an associate professor when first observed in the department and was awarded a $\mathrm{PhD}$ no more than ten years earlier. With the inclusion of prof and aspro the variables phd1, phd2 and phd3 better reflect the skills and knowledge associated with acquiring the qualification rather than the signal attached to the credential.

There are also control variables that capture attributes of the individual's work environment. The binary variable resuni, which equals one if the individual is employed in a research-intensive university, controls for broad institutional differences that might affect research productivity, both via recruitment practices and incentives for academics to undertake research. ${ }^{\text {xiv }}$ The variable size is the average number of academics in the department during the period 1996 through 2002. It is included to control for the effect of departmental scale on research productivity and on the propensity to co-author. ${ }^{\mathrm{xv}}$ Studstaff is defined as the number of effective, full-time, student units (EFTSU) per full-time equivalent (FTE) member of academic staff, measured at the university level and averaged across the years 1993 to 1996, inclusive, and is included to control for broad institutional differences in teaching loads which have been shown to adversely impact on research productivity. Resexpend is research expenditure (in \$000) per FTE academic staff in social sciences, measured in 1998. This is a proxy for university support for research at the broad discipline level, which includes Economics. ${ }^{\text {xvi }}$ 
Two versions of Equation (1) were estimated using the method of maximum likelihood: one with productivity measured in Q1-pages per year, the other with productivity measured in Q2-pages per year. The estimated coefficients and their levels of significance are displayed in Appendix 2 for Q1 output and Appendix 3 for Q2 output. The model was first estimated without the externality and co-authoring variables. The results appear in the column headed 'Specification 1'. All the coefficients have the expected signs and most are statistically significant. Given the nonlinear nature of the Tobit model, the average partial effects (APEs) of the explanatory variables are of more interest than the coefficients so Tables II and III display the APEs on expected Q1 and Q2 productivity, respectively, of all economists.

\{Table II here\}

\{Table III here\}

The APEs of the individual's human capital and other attributes, for the most part, are highly significant. The APEs of the three human capital variables, phd1, phd2 and phd3, indicate that having a $\mathrm{PhD}$ is very important for research productivity, particularly a PhD from a top 50 university in the case of Q1 publications. For example, in Specification 1 the APEs of phd1, 3.560 and 2.566 in Tables II and III (Row 1) respectively, imply that an economist with a $\mathrm{PhD}$ from a top 50 university has expected research productivity that is approximately $\left(\mathrm{e}^{3.560}=\right) 35$ times larger in the case of Q1 publications, and approximately $\left(\mathrm{e}^{2.566}=\right) 13$ times larger in the case of Q2 publications, than that of an economist without a PhD. These are large effects but as the median number of Q1 pages per year is zero and the median number of Q2 pages per year is 0.1 they are not unreasonably large.

Productivity declines with the years since the $\mathrm{PhD}$ was awarded, by about seven per cent per year in the case of Q1 publications and by a little more than three per cent 
per year for Q2 publications. The APE of female implies that the Q1 and Q2 productivity of females is about $\left(\mathrm{e}^{-0.471}=\right) 0.6$ and $\left(\mathrm{e}^{-0.388}=\right) 0.7$, respectively, that of males. ${ }^{\text {xvii }}$ The control variables, prof and aspro, indicate that academic status when first observed in the department is directly related to productivity during the following years. Compared with other academic economists in our data set, professors are $\left(\mathrm{e}^{2.262}=\right) 9.6$ and $\left(\mathrm{e}^{1.090}=\right) 3.0$ times more productive in Q1 and Q2 publications, respectively; 'fast-track’ associate professors are $\left(\mathrm{e}^{0.946}=\right) 2.6$ and $\left(\mathrm{e}^{0.620}=\right) 1.9$ times more productive, although the former is not statistically significant.

The APEs of the attributes of the academic's environment (resuni, size, studstaff and resexpend) in general, are not statistically significant, which is partially because there is a good deal of multicollinearity among these variables. Furthermore, studstaff and resexpend are measured at a more aggregated level than the department whereas there can be substantial variation among academics at the same university, and even in the same department, in terms of the number of students they teach and the amount of research funding they receive. ${ }^{\text {xiii }}$ However, as a group, the four variables make a statistically significant contribution and so they are retained in the model for control purposes.

\section{Human Capital Externality}

Lucas (1988) hypothesised that individual productivity increases with increases in the average human capital of one’s workplace peers, so we now investigate whether our results are consistent with this hypothesis The parameter of interest in Equation (1) is $\gamma_{0}$ and a crucial assumption for its unbiased estimation - an assumption made by FM and in this paper for the moment - is that the error term in Equation (1) is independent of the externality. Fox and Milbourne (2006) found that the research productivity of 
economists who responded to their survey increased with a proxy measure of the human capital of their departmental colleagues, namely their mean annual productivity over their lifetime.

By contrast, in Tables II and III, Specification 2, we include three direct measures of the human capital of one's departmental colleagues, namely the percentage of one's departmental colleagues who have a PhD from a top 50 university (hc1_coll), from a university ranked 51-150 (hc2_coll) and from a university of lower rank (hc3_coll). ${ }^{\mathrm{xix}}$ For Q1 productivity, a one percentage point increase in the percentage of one's colleagues with a $\mathrm{PhD}$ from a top 50 university is associated with an increase in one's own productivity of 4.3 per cent. The APE of $h c 2$ coll is 2.9 per cent but is statistically significant only at levels of significance in excess of ten per cent. The APE of $h c 3$ _coll is even smaller and is not statistically significant. Hence the largest statistically significant human capital effect is produced primarily by the most highly qualified subset of one’s departmental colleagues.

There is also a statistically significant positive association between the human capital of one's departmental colleagues and Q2 research output although its size is smaller and varies little with the quality of the PhD of one's colleagues: a one percentage point increase in the percentage of one's colleagues with a $\mathrm{PhD}$ from a top 50 university is associated with an increase in one’s own Q2 productivity by 1.9 per cent while the APEs of hc2_coll and hc3_coll are 2.0 per cent and 1.7 per cent, respectively. All these effects are statistically significant at the five per cent level.

So far, our results based on a direct measure of the human capital of one's colleagues are consistent with those of FM which are based on an indirect measure of their human capital. In this vein, and to further test the robustness of FM's results, we re-estimated our model but replaced educational qualifications of colleagues with the 
contemporaneous research productivity of one's departmental colleagues (the variable pub_coll) rather than their lifetime annual average because for a research externality to exist, colleagues must be present in the same department during the same period of time.

When pub_coll replaces hc1_coll, hc2_coll and hc3_coll in Tables II and III we get Specification 3. The APE of pub_coll on Q1 productivity is large and significant at the ten per cent level: a one-page increase per annum in the contemporaneous Q1 output of one’s departmental colleagues is associated with a 178.8 per cent increase in the individual's Q1 productivity. Once again, to put this in perspective keep in mind that on average academics in our data set have Q1 productivity of only 0.14 pages per annum and more than 50 per cent of academics have no Q1 output at all.

The APE of pub_coll on Q2 productivity is smaller, though statistically significant at the five per cent level: a one-page increase per annum in the contemporaneous Q2 output of one's departmental colleagues is associated with a 25.4 per cent increase in the individual's Q2 productivity. The mean and median Q2 productivities of academic economists in our data set are 0.83 and 0.10 pages per annum, respectively, which makes the APE of pub_coll modest in size. This result implies that individuals with contemporaneously more research-productive departmental colleagues are more productive, ceteris paribus, than individuals with colleagues who are less contemporaneously research productive. These results are again consistent with those in FM.

When pub_coll as well as hc1_coll, hc2_coll and hc3_coll are all included in the model (Specification 4 in Tables II and III) the APE of pub_coll on both Q1 and Q2 productivity is reduced in magnitude compared with Specification 3 and is no longer 
statistically significant. There is evidently a positive association between the human capital and the contemporaneous research productivity of one’s departmental colleagues because the APEs of hc1_coll on Q1 and Q2 productivity become smaller, and the latter is no longer significantly different from zero. However, the APEs of hc2_coll and hc3_coll on both Q1 and Q2 productivity are little changed compared with Specification 2. Although these results reinforce the conclusion in FM that the human capital effect is associated with the extent to which one's departmental colleagues are research active, our direct measure of the human capital of colleagues is better able to explain research productivity than the indirect measure in FM.

\section{Departmental Co-authoring}

Now we turn to the question of whether the human capital effect becomes manifest via co-authoring by departmental colleagues. Lucas (1988) conjectured that "...human capital accumulation is a social activity, involving groups of people in a way that has no counterpart in the accumulation of physical capital" (p.19, italics ours), and that "The external effects...have to do with the influences people have on the productivity of others, so the scope of such effects must have to do with the ways various groups interact..." (p.37, italics ours). Of course workplace interactions take many forms, most of which are not directly observable. ${ }^{\mathrm{xx}}$ However departmental coauthorship is both observable and measurable. Indeed in at least one department of which we are aware research incentive schemes have recently been established to encourage such collaboration.

Hence in Tables II and III, Specification 5, the variables hc1_coll, hc2_coll, hc3_coll and pub_coll in Specification 4 are replaced by the variable co-author, which is the percentage of each department's published pages that are co-authored by at least 
two colleagues from that department. This variable takes the same value for all academics in the same department. We find no evidence that co-authoring is associated with research productivity. To the contrary, the APE of co-author on both Q1 and Q2 research productivities is very small and not remotely statistically significant. The APEs of the other explanatory variables are approximately the same as in Specification $1 .{ }^{\mathrm{xxi}}$

Specification 6 includes both co-author and our direct measures of the human capital of one's departmental colleagues. The APE effect of co-author on Q1 productivity remains small and statistically insignificant, as it was in Specification 5. The APEs of hc1_coll, $h c 2$ _coll and $h c 3$ _coll on Q1 productivity retain approximately the same magnitudes and levels of significance as in Specification 2. These outcomes suggest there is little relationship between the propensity to co-author and the human capital of one's colleagues. However, the situation is a little different with respect to Q2 productivity in Specification 6 where the APE effect of co-author is small but positive and statistically significant at the five per cent level. Also, the APEs of hc1_coll, hc2_coll and hc3_coll on Q2 productivity increase slightly and become more statistically significant in Specification 6 compared with Specification 2. This is the only result in support of the hypothesis that more co-authorship at the departmental level enhances the research productivity of individual department members, although the effect is small: a one percentage point increase in the percentage of departmental output that is co-authored is associated with a one per cent increase in one's own Q2 productivity. Hence we find little evidence overall that the human capital externality identified in FM and confirmed by the results in this study becomes manifest via departmental co-authoring. 


\section{Endogenous Externality}

So far we have assumed that the composition of one's departmental peer group is exogenously determined. But as many studies have shown, one's peer group is often a choice variable. In this case choices are likely made both by the individual at the time he or she is recruited and by the departmental members doing the recruiting, so it is quite possible that people with similar, unobservable attributes that influence research productivity and their acquired levels of human capital will end up as colleagues in the same department. If so then the human-capital externality is endogenous and the results reported above are likely to overstate the peer group effect. To obtain an unbiased estimator of the effect of the externality on individuals' productivity we now relax the assumption that the error term in Equation (1) is independent of the human capital externality. Rather, we augment Equation (1) with a second (reduced-form) equation of the form:

$$
\begin{aligned}
& \text { externality }=\pi_{0}+\pi_{1} \text { phd } 1+\pi_{2} \text { phd } 2+\pi_{3} \text { phd } 3+\pi_{4} \text { exp } \\
& +\pi_{5}(\text { phd } 1 * \text { exp })+\pi_{6}(\text { phd } 2 * \text { exp })+\pi_{7} \text { female }+\pi_{8} \text { prof }+\pi_{9} \text { aspro }+\pi_{10} \text { resuni } \\
& +\pi_{11} \text { size }+\pi_{12} \text { studstaff }+\pi_{13} \text { resexpend }+\pi_{14} I V+v
\end{aligned}
$$

where $I V$ is an instrumental variable which is correlated with the human capital of one's colleagues (that is, it is relevant) but is uncorrelated with the error term in Equation (1) (that is, it is exogenous).

We reason that departments in highly prestigious universities will tend to attract members who share unobservable but productivity enhancing attributes such as motivation to do research. We considered several instruments that are proxies for the prestige of the university but which are unlikely to have a direct effect on an 
individual's research productivity once the explanatory variables in Equation (1) are taken into account. We settled on the year in which the university was founded, yrfounded, which ranges from 1850 for Sydney University to 1992 for RMIT University.

Since only hc1_coll is significant in Table II, $h c 2$ _coll and hc3_coll were dropped when assessing the effect of a human capital externality on Q1 research productivity. In other words, for Q1 research productivity, the dependent variable in Equation (2) is hc1_coll. The instrument, Yrfounded, passes the relevance test as its OLS coefficient in Equation (2) is statistically significant at the ten per cent level (its robust p-value is 0.059 ).

We re-estimated Specification 2 of the model with the (simplified) peer effect treated as exogenous, and then applied IV-Tobit where the peer effect is treated as endogenous and yrfounded is the instrumental variable. The APEs appear in columns 2-5 of Table IV. Whereas the APEs of the other explanatory variables, and their levels of significance, are very similar in the Tobit and IV-Tobit models, in the latter model the APE of the human capital of one's colleagues, hc1_coll, is halved in size from 0.045 to 0.024 and is no longer statistically significant. This result, which is consistent with those of related studies such as Evans et al. (1992), suggests that the effect of one’s departmental peer group on Q1 research productivity can largely be attributed to the choices that individuals make concerning departmental membership.

\{Table IV here

For Q2 research productivity, all of hc1_coll, hc2_coll and hc3_coll are significantly different from zero, but not significantly different from one another, in Table III so the externality was simplified to hc123_coll (the proportion of one’s colleagues with a PhD) in Table IV. That is, the dependent variable in Equation (2) 
for Q2 research productivity is hc123_coll. The instrument, Yrfounded, passes the relevance test as its OLS coefficient in Equation (2) is statistically significant at the five per cent level (its robust p-value is 0.049).

Specification 2 of the model was estimated, first with the (aggregated) peer effect treated as exogenous and then with it treated as endogenous and yrfounded as the instrumental variable. The APEs appear in the last four columns of Table IV. The APE of the human capital of one's colleagues is doubled in size and remains statistically significant at the five per cent level. A one per cent increase in the human capital of one's colleagues is now associated with a 3.5 (rather than a 1.8) per cent increase in the individual's Q2 research productivity. Therefore, there remains evidence of a humancapital externality when research output is more broadly defined.

\section{CONCLUSIONS}

This study has investigated whether a positive human capital externality existed in Australian economics departments from 1996 to 2000, as measured by the number of quality-adjusted pages published per year in scholarly journals. We extended the work of Fox and Milbourne (2006) by using a direct, rather than an indirect, measure of the human capital of one's departmental colleagues. On the assumption that the human capital externality is exogenous, we found that a one percentage point increase in the percentage of one's departmental colleagues with a PhD from a top 50 university is associated with an increase in one's annual research productivity of 4.3 per cent for publications in high quality journals, and 1.9 per cent for publications in a much broader range of journals. To put this into some perspective, for a department with around twenty members, the addition of one more 
member with a top-50 $\mathrm{PhD}$ would be associated with an annual Q1 (Q2) productivity increase of around twenty (nine) per cent.

We also found that the contemporaneous productivity of one's departmental colleagues is associated with a large positive effect on the individual's productivity, which is consistent with the assertion in Fox and Milbourne (2006) that the externality is driven primarily by the extent to which one’s departmental colleagues are research active. However, once we controlled for the educational qualifications of one's colleagues, the contemporaneous productivity effect was no longer apparent.

The way in which the association between individual productivity and the human capital of departmental colleagues becomes manifest remains unclear but, after controlling for other factors, we find no evidence that it does so via departmental coauthoring. Whilst we have not investigated whether individuals improve their own productivity by co-authoring (only whether an environment where co-authoring is common has a positive impact on productivity) and there may be other reasons for encouraging collaboration between colleagues, this finding casts doubt on the efficacy of departmental research incentive schemes which seek to encourage co-authorship as a way of boosting research productivity. It is possible that co-authoring is a response to workplace conditions or personal attributes that have a negative effect on research productivity and which, not being included in the model, impart a negative bias to our measure of the effect of co-authoring on productivity. On the other hand, there are mechanisms other than co-authoring that may be associated with a human capital externality. For example, there may be demonstration effects, peer pressure effects or competition to out-publish one's colleagues among academics with high levels of human capital. Alternatively there may be a weaker form of cooperative interaction where people contribute to each other's research output via informal feedback on 
working papers, in seminars, and so on without requiring 'payment' in the form of coauthorship. Sorting out these influences remains a topic for further research.

A related question, which we do not investigate here, is whether the wide disparities in co-authorship rates across departments observed in the late 1990s have persisted in the decade since 2000 when research has become increasingly important to career advancement and, if so, why such large differences exist in what might be regarded as one aspect of departmental 'tradition'.

Our results are based on aggregated research output data that does not differentiate by field of research within the economics profession. It is plausible that human capital externalities, and the productivity returns to departmental co-authorship or other forms of collaboration, are greater in some fields than in others. For example, applied microeconomic research requires a sound understanding of the relevant theory, data manipulation techniques and econometric capabilities and so may be more conducive to departmental collaboration than, say, research on theoretical economics. This paper does not investigate this issue, so it is also a topic of future research.

Whilst most of the results in this study are consistent with the existence of a positive human capital externality in Australian economics departments, they are based on the assumption that departmental peer effects are exogenously determined. When we allowed for endogeneity, the effect of the human capital externality disappeared completely in the case of Q1 research productivity. This does not imply that peer effects are unimportant but rather that the productivity effect is to some extent a choice variable under the control of individuals. One possible implication of these results is the desirability of departmental members being fully involved in recruitment processes so as to maximise the chances that all possible synergies from 
the exercise of choice by both parties can be realised. For example, departments might invite applicants to the campus for several days so as to allow both parties time to get to know each other.

For Q2 research productivity, the peer effect remains even after controlling for endogeneity. This result suggests that in general, increasing the proportion of departmental members with a $\mathrm{PhD}$ would result in an increase in research productivity more broadly defined, not only because individuals with a $\mathrm{PhD}$ are more productive than those without, but also because individuals with a $\mathrm{PhD}$ positively influence the productivity of their colleagues.

Finally, our study (as well as FM) is based on an implicit assumption that one's peer group is comprised of one's departmental colleagues. But as Manski (2000) has noted, the relevant peer group is often not obvious. Indeed our data on coauthorship in Table I suggests that for many individuals in many departments the relevant peer group is not likely to be comprised of only their departmental colleagues. If this is so then our results must be treated with considerable caution. "However severe the (task of establishing causation) may be when group composition is known, the problem becomes insurmountable when group composition is unknown” (Manski, 2000, p.129, term in italics ours). 


\section{References}

Axarlaglou, K. and V. Theoharakis 2003, Diversity in Economics: An Analysis of Journal Quality Perceptions, Mimeo, Athens Laboratory of Business Administration.

Battu, H., Belfield, C. and P. Sloane 2003, 'Human Capital Spillovers within the Workplace: Evidence for Great Britain’, Oxford Bulletin of Economics and Statistics, vol. 65, pp. 575-94.

Borjas,G. J. and K. Doran 2012, 'The Collapse of the Soviet Union and the Productivity of American Mathematicians', The Quarterly Journal of Economics, vol. 127, pp. 1143-1203.

Cameron, A.C. and P.K. Trevedi 2009, Microeconometrics Using STATA. College Station, TX: Stata Press.

Combes, P. P. and L. Linnemer 2003, 'Where are the Economists who Publish? Publication Concentration and Rankings in Europe based on Cumulative Publications', Journal of the European Economic Association, vol. 1, pp. 1250-1308.

Evans, W. N., Oates, W.E. and R. M. Schwab 1992, 'Measuring Peer Group Effects: A Study of Teenage Behavior', Journal of Political Economy, vol. 100, pp. 966-91.

Fox, K. and R. Milbourne 1999, 'What Determines Research Output of Academic Economists?’, The Economic Record, vol. 75, pp. 256-67.

Fox, K. and R. Milbourne 2006, 'Is it Harder to Soar with Eagles when you Work with Turkeys?’, Australian Economic Papers, vol. 45, December, pp. 362-71.

Gibson, J. 2000, 'Research Productivity in New Zealand University Economics Departments: Comments and Updates', New Zealand Economic Papers, vol. 34, pp. 73-87.

Guryan, J., Kroft, K. and M. Notowidigdo 2009, 'Peer Effects in the Workplace: Evidence from Random Groupings in Professional Golf Tournaments', American Economic Journal: Applied Economics, vol. 1, pp. 34-68.

Hirsch, B. T., Austin, R., Brooks, J. and J.B. Moore 1984, 'Economics Departmental Rankings: Comment [Economics Departmental Rankings: Research Incentives, Constraints, and Efficiency]', American Economic Review, vol. 74, pp. 822-826.

Kalaitzidakis, P., Mamuneas, T.P. and T. Stengos 2003, 'Rankings of Academic Journals and Institutions in Economics', Journal of the European Economic Association, vol. 1, pp. 1346-66.

Lubrano, M., Kirman, A., Bauwens, L. and C. Protopopescu 2003, 'Ranking Economics Departments in Europe: A Statistical Approach', Journal of the European Economic Association, vol. 1, pp. 1367-1401.

Lucas, R. 1988, 'On the Mechanics of Economic Development', Journal of Monetary Economics, vol. 22, pp. 3-42.

Manski, C.F. 2000, 'Economic Analysis of Social Interactions', Journal of Economic Perspectives, 14, pp. 115-136.

Mas, A. and E. Moretti 2009, 'Peers at Work', American Economic Review, vol. 99, pp. 112-145. 
Mason, P., Steagall, J. and M. Fabritius 1997, 'Economics Journal Rankings by Type of School: Perceptions Versus Citations', Quarterly Journal of Business and Economics, vol. 36, pp. 69-79.

Neary, J. P., Mirrlees, J.A. and J. Tirole 2003, 'Evaluating Economics Research in Europe: An Introduction', Journal of the European Economic Association, vol. 1, pp. 1239-49.

Oswald, A. J. 2007, 'An Examination of the Reliability of Prestigious Scholarly Journals: Evidence and Implications for Decision-Makers’, Economica, vol. 74, pp. 21-31.

Pomfret, R. and L. C. Wang 2003, 'Evaluating the Research Output of Australian Universities' Economics Departments’, Australian Economic Papers, vol. 42, pp. 418-41.

Rodgers, J. and F. Neri 2007, 'Research Productivity of Australian Academic Economists: Human-Capital and Fixed Effects’, Australian Economic Papers, vol. 46, pp. 67-87.

Sauer, R. D. 1988, 'Estimates of the Returns to Quality and Co-authorship in Economic Academia', Journal of Political Economy, vol. 96, pp. 855-66.

Sinha, D. and J. Macri 2002, 'Rankings of Australian Economics Departments, 19882000’, Economic Record, vol. 78, pp. 136-46.

Thursby, J. G. 2000, 'What Do We Say About Ourselves and What Does It Mean? Yet Another Look at Economics Department Research', Journal of Economics Literature, vol. 38, pp. 383-404.

Towe, J. B. and D. J. Wright 1995, 'Research Published by Australian Economics and Econometrics Departments: 1988-93’, Economic Record, vol. 71, pp. 8-17.

Wooldridge, J. M. 2009, Introductory Econometrics: A Modern Approach. 4th ed. Cincinnati, OH: South-Western. 
Table I Research Productivity and Co-authorship 1998-2002

\begin{tabular}{|c|c|c|c|c|c|c|c|c|}
\hline \multirow[b]{2}{*}{$\begin{array}{l}\text { Depts } \\
\text { (1) }\end{array}$} & \multicolumn{4}{|c|}{ Q1 Research Productivity } & \multicolumn{4}{|c|}{ Q2 Research Productivity } \\
\hline & $\begin{array}{c}\text { Active } \\
\text { (\%) } \\
(2) \\
\end{array}$ & $\begin{array}{c}\text { Pages } \\
\text { per yr } \\
\text { if active } \\
(3)\end{array}$ & $\begin{array}{c}\text { Pages } \\
\text { per yr } \\
\text { (all) } \\
(4)\end{array}$ & $\begin{array}{c}\text { \%Co- } \\
\text { author } \\
(5) \\
\end{array}$ & $\begin{array}{c}\text { Active } \\
\text { (\%) } \\
(6) \\
\end{array}$ & $\begin{array}{c}\text { Pages } \\
\text { per yr } \\
\text { if active } \\
(7)\end{array}$ & $\begin{array}{c}\text { Pages } \\
\text { per yr } \\
\text { (all) } \\
(8)\end{array}$ & $\begin{array}{c}\text { \%Co- } \\
\text { author } \\
(9)\end{array}$ \\
\hline Adelaide & 50 & 0.40 & 0.20 & 2.6 & 65 & 2.05 & 1.34 & 2.5 \\
\hline ANU & 83 & 0.80 & 0.66 & 11.8 & 86 & 2.01 & 1.73 & 14.6 \\
\hline Canberra & 17 & 0.00 & 0.00 & 0.0 & 25 & 0.19 & 0.05 & 11.8 \\
\hline Curtin & 54 & 0.14 & 0.07 & 12.0 & 82 & 0.97 & 0.77 & 11.6 \\
\hline Deakin & 43 & 0.18 & 0.08 & 6.1 & 59 & 1.27 & 0.76 & 14.2 \\
\hline E.Cowan & 7 & 0.03 & 0.00 & 0.0 & 13 & 0.64 & 0.08 & 0.0 \\
\hline Flinders & 30 & 0.26 & 0.08 & 9.4 & 30 & 2.37 & 0.72 & 11.8 \\
\hline Griffith & 21 & 0.03 & 0.01 & 0.0 & 64 & 0.28 & 0.18 & 8.7 \\
\hline JCU & 19 & 2.68 & 0.50 & 0.0 & 34 & 5.40 & 1.86 & 0.0 \\
\hline LaTrobe & 58 & 0.25 & 0.15 & 17.2 & 68 & 1.74 & 1.18 & 13.0 \\
\hline Macquarie & 14 & 0.07 & 0.01 & 1.6 & 41 & 0.72 & 0.29 & 3.7 \\
\hline Melbourne & 72 & 0.55 & 0.40 & 6.5 & 87 & 3.18 & 2.77 & 14.4 \\
\hline Monash & 40 & 0.48 & 0.19 & 1.1 & 54 & 1.34 & 0.73 & 11.4 \\
\hline Murdoch & 25 & 0.03 & 0.01 & 0.0 & 55 & 1.31 & 0.72 & 16.9 \\
\hline NewEng. & 62 & 0.08 & 0.05 & 34.8 & 86 & 0.50 & 0.44 & 6.9 \\
\hline Newcastle & 13 & 0.04 & 0.01 & 0.0 & 59 & 0.35 & 0.21 & 12.1 \\
\hline NSW & 55 & 0.69 & 0.38 & 12.0 & 69 & 2.24 & 1.55 & 10.8 \\
\hline QLD & 39 & 0.08 & 0.03 & 0.0 & 77 & 1.07 & 0.83 & 7.5 \\
\hline QUT & 13 & 0.10 & 0.01 & 0.0 & 35 & 0.78 & 0.28 & 18.6 \\
\hline RMIT & 19 & 0.03 & 0.01 & 22.9 & 30 & 1.08 & 0.32 & 73.9 \\
\hline Sydney & 32 & 0.13 & 0.04 & 0.9 & 66 & 0.80 & 0.52 & 0.4 \\
\hline Tasmania & 69 & 0.24 & 0.17 & 6.1 & 81 & 2.69 & 2.18 & 12.5 \\
\hline UTS & 13 & 0.22 & 0.03 & 33.3 & 49 & 0.40 & 0.20 & 36.3 \\
\hline VUT & 12 & 0.05 & 0.01 & 74.5 & 28 & 0.38 & 0.11 & 61.1 \\
\hline W Aust & 58 & 1.14 & 0.66 & 0.8 & 70 & 3.08 & 2.15 & 1.3 \\
\hline W Sydney & 29 & 0.08 & 0.02 & 0.0 & 53 & 0.64 & 0.33 & 2.3 \\
\hline W'gong & 15 & 0.06 & 0.01 & 64.6 & 61 & 0.53 & 0.32 & 24.2 \\
\hline Correlation & & & & -0.18 & & & & -0.27 \\
\hline
\end{tabular}




\begin{tabular}{|c|c|c|c|c|c|c|c|c|c|c|c|c|}
\hline & \multicolumn{2}{|c|}{ Specification 1} & \multicolumn{2}{|c|}{ Specification 2} & \multicolumn{2}{|c|}{ Specification 3} & \multicolumn{2}{|c|}{ Specification 4} & \multicolumn{2}{|c|}{ Specification 5} & \multicolumn{2}{|c|}{ Specification 6} \\
\hline & $\underline{\mathrm{APE}}$ & p-value & $\underline{\mathrm{APE}}$ & p-value & APE & p-value & APE & p-value & APE & p-value & APE & p-value \\
\hline phd1 & 3.560 & 0.000 & 3.295 & 0.000 & 3.459 & 0.000 & 3.249 & 0.000 & 3.564 & 0.000 & 3.299 & 0.000 \\
\hline phd2 & 2.432 & 0.000 & 2.289 & 0.000 & 2.420 & 0.000 & 2.300 & 0.000 & 2.434 & 0.000 & 2.287 & 0.000 \\
\hline phd3 & 2.291 & 0.000 & 2.324 & 0.000 & 2.303 & 0.000 & 2.320 & 0.000 & 2.301 & 0.000 & 2.335 & 0.000 \\
\hline $\exp$ & -0.068 & 0.000 & -0.070 & 0.000 & -0.065 & 0.000 & -0.068 & 0.000 & -0.069 & 0.000 & -0.070 & 0.000 \\
\hline gender & -0.471 & 0.078 & -0.510 & 0.038 & -0.469 & 0.066 & -0.496 & 0.046 & -0.468 & 0.084 & -0.507 & 0.041 \\
\hline prof & 2.262 & 0.000 & 2.281 & 0.000 & 2.207 & 0.000 & 2.256 & 0.000 & 2.277 & 0.000 & 2.299 & 0.000 \\
\hline aspro & 0.946 & 0.151 & 0.932 & 0.137 & 0.943 & 0.143 & 0.927 & 0.138 & 0.950 & 0.149 & 0.933 & 0.135 \\
\hline resuni & 0.407 & 0.392 & 0.000 & 1.000 & 0.252 & 0.602 & -0.033 & 0.927 & 0.505 & 0.322 & 0.128 & 0.772 \\
\hline size & -0.009 & 0.592 & -0.022 & 0.122 & -0.007 & 0.655 & -0.018 & 0.168 & -0.012 & 0.497 & -0.026 & 0.086 \\
\hline studstaff & -0.158 & 0.038 & -0.077 & 0.238 & -0.122 & 0.100 & -0.058 & 0.384 & -0.158 & 0.040 & -0.076 & 0.261 \\
\hline resexpend & 0.003 & 0.247 & 0.001 & 0.563 & 0.001 & 0.731 & 0.000 & 0.929 & 0.002 & 0.309 & 0.001 & 0.690 \\
\hline hc1_coll & & & 0.043 & 0.018 & & & 0.037 & 0.052 & & & 0.045 & 0.012 \\
\hline hc2_coll & & & 0.029 & 0.100 & & & 0.032 & 0.071 & & & 0.028 & 0.097 \\
\hline hc3_coll & & & 0.008 & 0.380 & & & 0.011 & 0.264 & & & 0.009 & 0.379 \\
\hline pub_coll & & & & & 1.788 & 0.091 & 1.184 & 0.339 & & & & \\
\hline intra & & & & & & & & & 0.004 & 0.725 & 0.006 & 0.574 \\
\hline
\end{tabular}

Standard errors are cluster-robust, where the clustering is by department. 


\begin{tabular}{|c|c|c|c|c|c|c|c|c|c|c|c|c|}
\hline & \multicolumn{2}{|c|}{ Specification 1} & \multicolumn{2}{|c|}{ Specification 2} & \multicolumn{2}{|c|}{ Specification 3} & \multicolumn{2}{|c|}{ Specification 4} & \multicolumn{2}{|c|}{ Specification 5} & \multicolumn{2}{|c|}{ Specification 6} \\
\hline & $\underline{\mathrm{APE}}$ & p-value & $\underline{\mathrm{APE}}$ & p-value & $\underline{\mathrm{APE}}$ & p-value & $\underline{\mathrm{APE}}$ & $\mathrm{p}$-value & $\underline{\mathrm{APE}}$ & p-value & $\underline{\mathrm{APE}}$ & p-value \\
\hline phd1 & 2.566 & 0.000 & 2.439 & 0.000 & 2.503 & 0.000 & 2.410 & 0.000 & 2.539 & 0.000 & 2.451 & 0.000 \\
\hline phd2 & 1.957 & 0.000 & 1.875 & 0.000 & 1.928 & 0.000 & 1.874 & 0.000 & 1.941 & 0.000 & 1.874 & 0.000 \\
\hline phd3 & 1.617 & 0.000 & 1.559 & 0.000 & 1.614 & 0.000 & 1.555 & 0.000 & 1.601 & 0.000 & 1.571 & 0.000 \\
\hline $\exp$ & -0.033 & 0.000 & -0.036 & 0.000 & -0.031 & 0.000 & -0.034 & 0.000 & -0.034 & 0.000 & -0.035 & 0.000 \\
\hline gender & -0.338 & 0.032 & -0.338 & 0.021 & -0.344 & 0.026 & -0.333 & 0.025 & -0.338 & 0.030 & -0.339 & 0.022 \\
\hline prof & 1.090 & 0.000 & 1.102 & 0.000 & 1.053 & 0.000 & 1.081 & 0.000 & 1.092 & 0.000 & 1.099 & 0.000 \\
\hline aspro & 0.620 & 0.036 & 0.548 & 0.058 & 0.614 & 0.039 & 0.544 & 0.064 & 0.619 & 0.036 & 0.520 & 0.076 \\
\hline resuni & 0.448 & 0.119 & 0.297 & 0.107 & 0.341 & 0.173 & 0.280 & 0.055 & 0.374 & 0.197 & 0.383 & 0.046 \\
\hline size & -0.002 & 0.862 & -0.004 & 0.630 & -0.001 & 0.937 & -0.001 & 0.895 & 0.002 & 0.874 & -0.012 & 0.055 \\
\hline studstaff & -0.013 & 0.689 & 0.037 & 0.206 & 0.007 & 0.832 & 0.045 & 0.085 & -0.010 & 0.738 & 0.052 & 0.103 \\
\hline resexpend & 0.003 & 0.040 & 0.003 & 0.005 & 0.002 & 0.020 & 0.002 & 0.001 & 0.003 & 0.023 & 0.002 & 0.017 \\
\hline hc1_coll & & & 0.019 & 0.046 & & & 0.013 & 0.137 & & & 0.029 & 0.001 \\
\hline hc2_coll & & & 0.020 & 0.046 & & & 0.021 & 0.010 & & & 0.026 & 0.007 \\
\hline hc3_coll & & & 0.017 & 0.001 & & & 0.017 & 0.000 & & & 0.024 & 0.000 \\
\hline pub_coll & & & & & 0.254 & 0.033 & 0.209 & 0.139 & & & & \\
\hline intra & & & & & & & & & -0.005 & 0.298 & 0.011 & 0.016 \\
\hline
\end{tabular}

Standard errors are cluster-robust, where the clustering is by department. 
Table IV Average Partial Effects on the log of Research Productivity of All Academics

\begin{tabular}{|l|r|r|r|r|r|r|r|r|}
\hline & \multicolumn{3}{|c|}{ Q1 research productivity } & \multicolumn{3}{c|}{ Q2 research productivity } \\
\hline & Tobit & p-value & $\underline{\text { IV-Tobit }}$ & p-value & $\underline{\text { Tobit }}$ & p-value & $\underline{\text { IV-Tobit }}$ & p-value \\
\hline phd1 & 3.387 & 0.000 & 3.464 & 0.000 & 2.452 & 0.000 & 2.347 & 0.000 \\
\hline phd2 & 2.289 & 0.000 & 2.345 & 0.000 & 1.879 & 0.000 & 1.811 & 0.000 \\
\hline phd3 & 2.326 & 0.000 & 2.309 & 0.000 & 1.553 & 0.000 & 1.489 & 0.000 \\
\hline exp & -0.067 & 0.000 & -0.068 & 0.000 & -0.036 & 0.000 & -0.038 & 0.000 \\
\hline gender & -0.540 & 0.033 & -0.520 & 0.050 & -0.336 & 0.024 & -0.336 & 0.019 \\
\hline prof & 2.222 & 0.000 & 2.242 & 0.000 & 1.102 & 0.000 & 1.103 & 0.000 \\
\hline aspro & 0.926 & 0.137 & 0.942 & 0.143 & 0.544 & 0.058 & 0.477 & 0.094 \\
\hline resuni & -0.037 & 0.934 & 0.209 & 0.722 & 0.320 & 0.089 & 0.144 & 0.588 \\
\hline size & -0.022 & 0.108 & -0.018 & 0.193 & -0.003 & 0.699 & -0.002 & 0.823 \\
\hline studstaff & -0.097 & 0.121 & -0.120 & 0.094 & 0.036 & 0.192 & 0.076 & 0.142 \\
\hline resexpend & 0.001 & 0.511 & 0.002 & 0.383 & 0.003 & 0.004 & 0.002 & 0.031 \\
\hline hc1_coll & 0.045 & 0.003 & 0.024 & 0.530 & & & & \\
\hline hc123_coll & & & & & 0.018 & 0.000 & 0.035 & 0.032 \\
\hline Standard errors are cluster-robust where the clustering is by department & & & \\
\hline
\end{tabular}




\section{Appendix 1}

\begin{tabular}{|c|c|}
\hline $\begin{array}{l}\text { Variable/Acro } \\
\text { nym }\end{array}$ & Definition \\
\hline phd1 & $\begin{array}{l}\text { A dummy variable = } 1 \text { if, in the first year from } 1996-2000 \text { that the } \\
\text { individual was employed in the department, he/she had a Ph.D } \\
\text { from an institution ranked 1-50 in Kalaitzidakis (2003). }\end{array}$ \\
\hline phd2 & $\begin{array}{l}\text { A dummy variable }=1 \text { if, in the first year from } 1996-2000 \text { that the } \\
\text { individual was employed in the department, he/she had a Ph.D } \\
\text { from an institution ranked 51-150 in Kalaitzidakis (2003). }\end{array}$ \\
\hline phd3 & $\begin{array}{l}\text { A dummy variable }=1 \text { if, in the first year from } 1996-2000 \text { that the } \\
\text { individual was employed in the department, he/she had a Ph.D } \\
\text { from an institution ranked } 150 \text { or greater in Kalaitzidakis (2003). }\end{array}$ \\
\hline $\exp$ & $\begin{array}{l}\text { Years between conferral of the Ph.D and the last year from 1996- } \\
2000 \text { that the individual was employed in the department. }\end{array}$ \\
\hline female & A dummy variable $=1$ if the individual is a female. \\
\hline prof & $\begin{array}{l}\text { A dummy variable }=1 \text { if the individual was a professor when first } \\
\text { observed in the department. }\end{array}$ \\
\hline aspro & $\begin{array}{l}\text { A dummy variable }=1 \text { if the individual was an associate professor } \\
\text { when first observed in the department and was awarded a Ph.D no } \\
\text { more than ten years earlier. }\end{array}$ \\
\hline resuni & $\begin{array}{l}\text { A dummy variable }=1 \text { if the individual was employed in a research } \\
\text { intensive university, i.e. Adelaide, ANU, Melbourne, Monash, } \\
\text { NSW, Queensland, Sydney, Tasmania or UWA. }\end{array}$ \\
\hline size & $\begin{array}{l}\text { The average number of academics in the department from } 1996 \text { to } \\
2002\end{array}$ \\
\hline studstaff & $\begin{array}{l}\text { The number of effective, full-time, student units per full-time } \\
\text { equivalent (FTE) member of academic staff, measured at the } \\
\text { university level and averaged across the years } 1993 \text { to } 1996 .\end{array}$ \\
\hline resexpend & $\begin{array}{l}\text { Resexpend is research expenditure (in \$000) per FTE academic } \\
\text { staff in social sciences, measured in } 1998 .\end{array}$ \\
\hline hc1_coll & $\begin{array}{l}\text { The percentage of departmental colleagues with a Ph.D from a } \\
\text { university ranked 1-50 in Kalaitzidakis (2003). }\end{array}$ \\
\hline hc2_coll & $\begin{array}{l}\text { The percentage of departmental colleagues with a Ph.D from a } \\
\text { university ranked 51-150 in Kalaitzidakis (2003). }\end{array}$ \\
\hline hc3_coll & $\begin{array}{l}\text { The percentage of departmental colleagues with a Ph.D from a } \\
\text { university ranked } 151 \text { or greater in Kalaitzidakis (2003). }\end{array}$ \\
\hline pub_coll & $\begin{array}{l}\text { The contemporaneous research productivity of an individual's } \\
\text { departmental colleagues. }\end{array}$ \\
\hline co-author & $\begin{array}{l}\text { The percentage of departmental published pages that involve co- } \\
\text { authoring with at least one colleague from the same department. }\end{array}$ \\
\hline
\end{tabular}




\begin{tabular}{|c|c|c|c|c|c|c|c|c|c|c|c|c|}
\hline \multicolumn{13}{|c|}{ Appendix 2 Tobit Estimation of the log of Q1 Research Productivity } \\
\hline & \multicolumn{2}{|c|}{ Specification 1} & \multicolumn{2}{|c|}{ Specification 2} & \multicolumn{2}{|c|}{ Specification 3} & \multicolumn{2}{|c|}{ Specification 4} & \multicolumn{2}{|c|}{ Specification 5} & \multicolumn{2}{|c|}{ Specification 6} \\
\hline & $\underline{\text { coeff }}$ & p-value & $\underline{\text { coeff }}$ & p-value & $\underline{\text { coeff }}$ & p-value & $\underline{\text { coeff }}$ & p-value & $\underline{\text { coeff }}$ & p-value & $\underline{\text { coeff }}$ & p-value \\
\hline phd1 & 12.393 & 0.000 & 11.706 & 0.000 & 12.112 & 0.000 & 11.576 & 0.000 & 12.409 & 0.000 & 11.715 & 0.000 \\
\hline phd2 & 9.661 & 0.000 & 9.236 & 0.000 & 9.574 & 0.000 & 9.232 & 0.000 & 9.678 & 0.000 & 9.239 & 0.000 \\
\hline phd3 & 8.814 & 0.000 & 8.816 & 0.000 & 8.774 & 0.000 & 8.772 & 0.000 & 8.859 & 0.000 & 8.862 & 0.000 \\
\hline $\exp$ & -0.124 & 0.009 & -0.136 & 0.003 & -0.117 & 0.019 & -0.133 & 0.005 & -0.125 & 0.007 & -0.138 & 0.002 \\
\hline exp*phd1 & -0.150 & 0.040 & -0.125 & 0.071 & -0.144 & 0.043 & -0.123 & 0.075 & -0.148 & 0.040 & -0.122 & 0.076 \\
\hline exp*phd2 & -0.064 & 0.380 & -0.056 & 0.425 & -0.065 & 0.370 & -0.057 & 0.417 & -0.063 & 0.390 & -0.054 & 0.440 \\
\hline gender & -1.354 & 0.106 & -1.469 & 0.063 & -1.346 & 0.094 & -1.425 & 0.072 & -1.343 & 0.113 & -1.461 & 0.067 \\
\hline prof & 4.975 & 0.000 & 5.010 & 0.000 & 4.868 & 0.000 & 4.962 & 0.000 & 5.001 & 0.000 & 5.042 & 0.000 \\
\hline aspro & 2.402 & 0.098 & 2.369 & 0.089 & 2.392 & 0.093 & 2.356 & 0.090 & 2.413 & 0.096 & 2.372 & 0.088 \\
\hline resuni & 1.101 & 0.398 & 0.000 & 1.000 & 0.683 & 0.606 & -0.089 & 0.927 & 1.364 & 0.330 & 0.345 & 0.774 \\
\hline size & -0.025 & 0.597 & -0.059 & 0.127 & -0.019 & 0.657 & -0.049 & 0.169 & -0.034 & 0.505 & -0.071 & 0.092 \\
\hline studstaff & -0.427 & 0.038 & -0.209 & 0.250 & -0.330 & 0.100 & -0.158 & 0.391 & -0.428 & 0.041 & -0.207 & 0.274 \\
\hline resexpend & 0.007 & 0.240 & 0.003 & 0.557 & 0.002 & 0.729 & 0.000 & 0.928 & 0.006 & 0.301 & 0.002 & 0.687 \\
\hline hc1_coll & & & 0.117 & 0.011 & & & 0.100 & 0.041 & & & 0.121 & 0.007 \\
\hline hc2_coll & & & 0.079 & 0.108 & & & 0.085 & 0.074 & & & 0.076 & 0.105 \\
\hline hc3_coll & & & 0.022 & 0.372 & & & 0.029 & 0.256 & & & 0.024 & 0.371 \\
\hline pub_coll & & & & & 4.849 & 0.095 & 3.205 & 0.344 & & & & \\
\hline co-author & & & & & & & & & 0.010 & 0.726 & 0.015 & 0.576 \\
\hline constant & -11.336 & 0.002 & -17.134 & 0.000 & -13.110 & 0.000 & -18.356 & 0.000 & -11.322 & 0.002 & -17.195 & 0.000 \\
\hline sigma & 6.465 & 0.000 & 6.372 & 0.000 & 6.424 & 0.000 & 6.357 & 0.000 & 6.463 & 0.000 & 6.367 & 0.000 \\
\hline log-like'd & \multicolumn{2}{|c|}{-1182} & \multicolumn{2}{|c|}{-1173} & \multicolumn{2}{|c|}{-1179} & \multicolumn{2}{|c|}{-1172} & \multicolumn{2}{|c|}{-1181} & \multicolumn{2}{|c|}{-1173} \\
\hline
\end{tabular}

Standard errors are cluster-robust, where the clustering is by department. 


\begin{tabular}{|c|c|c|c|c|c|c|c|c|c|c|c|c|}
\hline \multicolumn{13}{|c|}{ Appendix 3 Tobit Estimation of the log of Q2 Research Productivity } \\
\hline & \multicolumn{2}{|c|}{ Specification 1} & \multicolumn{2}{|c|}{ Specification 2} & \multicolumn{2}{|c|}{ Specification 3} & \multicolumn{2}{|c|}{ Specification 4} & \multicolumn{2}{|c|}{ Specification 5} & \multicolumn{2}{|c|}{ Specification 6} \\
\hline & $\underline{\text { coeff }}$ & p-value & $\underline{\text { coeff }}$ & p-value & $\underline{\text { coeff }}$ & p-value & $\underline{\text { coeff }}$ & p-value & $\underline{\text { coeff }}$ & p-value & $\underline{\text { coeff }}$ & p-value \\
\hline phd1 & 5.396 & 0.000 & 5.130 & 0.000 & 5.279 & 0.000 & 5.080 & 0.000 & 5.343 & 0.000 & 5.143 & 0.000 \\
\hline phd2 & 4.309 & 0.000 & 4.131 & 0.000 & 4.241 & 0.000 & 4.115 & 0.000 & 4.273 & 0.000 & 4.135 & 0.000 \\
\hline phd3 & 3.376 & 0.000 & 3.246 & 0.000 & 3.347 & 0.000 & 3.228 & 0.000 & 3.338 & 0.000 & 3.276 & 0.000 \\
\hline $\exp$ & -0.022 & 0.253 & -0.030 & 0.119 & -0.019 & 0.328 & -0.028 & 0.154 & -0.024 & 0.222 & -0.029 & 0.127 \\
\hline exp*phd1 & -0.089 & 0.000 & -0.081 & 0.001 & -0.087 & 0.000 & -0.080 & 0.001 & -0.088 & 0.000 & -0.079 & 0.001 \\
\hline exp*phd2 & -0.052 & 0.025 & -0.049 & 0.028 & -0.051 & 0.028 & -0.048 & 0.031 & -0.052 & 0.025 & -0.048 & 0.031 \\
\hline gender & -0.613 & 0.042 & -0.613 & 0.029 & -0.625 & 0.034 & -0.603 & 0.034 & -0.614 & 0.039 & -0.615 & 0.031 \\
\hline prof & 1.698 & 0.000 & 1.716 & 0.000 & 1.645 & 0.000 & 1.685 & 0.000 & 1.701 & 0.000 & 1.712 & 0.000 \\
\hline aspro & 1.023 & 0.026 & 0.912 & 0.046 & 1.011 & 0.029 & 0.906 & 0.051 & 1.021 & 0.026 & 0.869 & 0.062 \\
\hline resuni & 0.769 & 0.115 & 0.514 & 0.103 & 0.588 & 0.174 & 0.484 & 0.054 & 0.644 & 0.193 & 0.660 & 0.042 \\
\hline size & -0.003 & 0.862 & -0.006 & 0.629 & -0.001 & 0.937 & -0.002 & 0.895 & 0.003 & 0.874 & -0.020 & 0.051 \\
\hline studstaff & -0.023 & 0.689 & 0.064 & 0.202 & 0.011 & 0.832 & 0.079 & 0.083 & -0.018 & 0.739 & 0.091 & 0.097 \\
\hline resexpend & 0.005 & 0.041 & 0.005 & 0.005 & 0.004 & 0.021 & 0.004 & 0.001 & 0.005 & 0.024 & 0.004 & 0.017 \\
\hline hc1_coll & & & 0.034 & 0.041 & & & 0.022 & 0.135 & & & 0.051 & 0.001 \\
\hline hc2_coll & & & 0.035 & 0.052 & & & 0.036 & 0.011 & & & 0.046 & 0.008 \\
\hline hc3_coll & & & 0.030 & 0.001 & & & 0.030 & 0.000 & & & 0.043 & 0.000 \\
\hline pub_coll & & & & & 0.443 & 0.033 & 0.365 & 0.135 & & & & \\
\hline co-author & & & & & & & & & -0.009 & 0.292 & 0.020 & 0.015 \\
\hline constant & -6.038 & 0.000 & -9.182 & 0.000 & -6.810 & 0.000 & -9.579 & 0.000 & -6.038 & 0.000 & -10.504 & 0.000 \\
\hline sigma & 2.754 & 0.000 & 2.730 & 0.000 & 2.741 & 0.000 & 2.723 & 0.000 & 2.753 & 0.000 & 2.722 & 0.000 \\
\hline log-like'd & \multicolumn{2}{|c|}{-1331} & \multicolumn{2}{|c|}{-1322} & \multicolumn{2}{|c|}{-1329} & \multicolumn{2}{|c|}{-1321} & \multicolumn{2}{|c|}{-1330} & \multicolumn{2}{|c|}{-1320} \\
\hline
\end{tabular}

Standard errors are cluster-robust, where the clustering is by department. 
${ }^{\mathrm{i}}$ See Battu et al. (2003) for a detailed discussion of positive and negative human capital externalities within workplaces in Great Britain.

ii See Fox and Milbourne (1999) for details on the questionnaire used and the data thereby obtained.

${ }^{\text {iii }}$ FM do not control for peer group endogeneity, as they note in their footnote 1 . However in their conclusion they dismiss this omission: "As our modelling approach controls for individual characteristics when examining the explanatory power of colleagues' research output, we are not simply capturing the tendency of research-intensive economics departments to hire academic staff with high research output or potential” (p.369). We believe it is unlikely that all relevant explanatory variables can be included in a single equation model and so we believe that our instrumental variables approach makes a useful contribution in this area.

${ }^{\text {iv }}$ We excluded the following universities either because they did not offer a doctoral degree in economics or because of data limitations: Australian Defence Force Academy, Charles Darwin, Charles Sturt, Swinburne University of Technology, Southern Cross and the University of Southern Queensland.

${ }^{\mathrm{v}}$ We acknowledge that our study period is somewhat dated. However one advantage of this is that we have established a benchmark, in a period where research productivity was less emphasised than it is currently (by, for example, the ERA 2012 departmental rankings). Hence subsequent investigations into this area will be able to investigate whether the additional institutional attention and funding devoted to increasing research productivity has paid dividends.

${ }^{\mathrm{vi}}$ In cases where a co-author had the same Australian economics department affiliation but did not appear on our staff list, we assumed the person to be a student or academic from another department or research centre within the same university.

vii This is supported by research suggesting that the returns to non-refereed publications are low, at least in other countries. See Gibson (2000) and Sauer (1988). Nevertheless, we acknowledge that the decision to focus entirely on journal articles is controversial.

viii Our analysis is based on 'standardised' pages calculated with page-conversion factors for 391 journals provided to us by Sinha and Macri (2002). For other journals we used the average conversion factor of all 'group 4 journals' in Sinha and Macri (2002). The reference journal, with a weight of one, is the American Economic Review.

${ }^{\text {ix }}$ See Neary, Mirrlees and Tirole (2003), Figure 1 for an illustrative summary of the wide range of weighting schemes used in the literature to take account of journal quality. See also Combes and Linnemer (2003), Lubrano et al. (2003), Axarlaglou and Theoharakis (2003), Mason, Steagall and Fabritius (1997) and Thursby (2000).

${ }^{x}$ See Combes and Linnemer (2003), Lubrano et al. (2003) and Kalaitzidakis et al. (2003) for international rankings.

${ }^{x i}$ See Appendix 1 for definitions of all variables and acronyms used in this paper.

xii The Tobit I model assumes that each explanatory variable has the same effect on the probability of publishing as on the (log of the) number of pages published, given some publications were achieved. We checked this following the procedure suggested by Wooldridge (2009, p.595). A Probit model with the same explanatory variables was estimated and found to have coefficients with the same sign and of approximately the same magnitude as those of the Tobit I model.

xiii We used the rankings of PhD granting institutions in Kalaitzidakis et al. (2003) after confirming their stability over time using the rankings of Hirsch et al. (1984).

${ }^{\text {xiv }}$ The research intensive universities in our study are Adelaide, ANU, Melbourne, Monash, New South Wales, Queensland, Sydney, Tasmania and Western Australia.

${ }^{\mathrm{xv}}$ The inclusion of the variable size takes account of the fact that large departments offer more opportunity for co-authoring than small departments. If productivity is inversely related to department size ceteris paribus, and if more co-authoring occurs in large departments than in small departments, then excluding size would create a downward bias in the estimated effect of co-authoring. A better control would be the number of departmental colleagues with the same field of interest or with complementary skills, but the data on these characteristics are not available.

${ }^{x v i}$ The last two explanatory variables in our model, externality and co-author, are discussed below.

${ }^{x v i i}$ This result may be due to female academics experiencing more career disruptions, and/or having higher teaching loads, than their male departmental colleagues. Due to data limitations our model does not control for either of these variables.

${ }_{\text {xviii }}$ In separate regressions, results from which are not reported here, we included $s i z e^{2}$ and $\exp ^{2}$ in an attempt to control for possible non-linear effects of departmental size and individual experience on research productivity. The coefficient estimate on size $e^{2}$ was statistically insignificant. The coefficient 
estimate on $\exp ^{2}$ was significant at the 5 per cent level but was positive in sign and so small in magnitude as to be of no practical concern.

${ }^{x i x}$ The residual category is the proportion of one's co-workers without a $\mathrm{PhD}$.

${ }^{\mathrm{xx}}$ We assume that professional interactions in academia occur for the purpose of production rather than consumption.

${ }^{\mathrm{xxi}}$ This result is unchanged if the percentage of departmental research output that is co-authored with colleagues external to the department is included in the model. 